\title{
Multi-tasking uncovers right spatial neglect and extinction in chronic left-hemisphere stroke patients
}

Elvio Blini ${ }^{1}$, Zaira Romeo ${ }^{2}$, Chiara Spironelli ${ }^{2,3}$, Marco Pitteri ${ }^{4}$, Francesca Meneghello ${ }^{5}$, Mario Bonato ${ }^{6 *}$, and Marco Zorzi $i^{2,3,5 *}$

1 Department of Developmental Psychology and Socialization, University of Padova, Padua, Italy 2 Department of General Psychology, University of Padova, Padua, Italy

3 Center for Cognitive Neuroscience, University of Padova, Padua, Italy

4 Neurology section, Department of Neurological and Movement Sciences, University of Verona, Verona, Italy

5 IRCCS San Camillo Hospital, Lido Venice, Italy

6 Department of Experimental Psychology, Ghent University, Ghent, Belgium

\section{Keywords:}

Unilateral Spatial Neglect; Attentional Load; Dual Task; Left Hemisphere Damage; Extinction; Stroke; Spatial Awareness

\section{Word Count:}

Abstract: 202

Main text: 8440 (including references)

\section{${ }^{*}$ Corresponding authors:}

Prof. Marco Zorzi, Dipartimento di Psicologia Generale, via Venezia 8, 35131 Padova (Italy). Email: marco.zorzi@unipd.it

Dr. Mario Bonato, Department of Experimental Psychology, Ghent University, Henri Dunantlaan 2, B-9000 Ghent, Belgium. Email: mario.bonato@ugent.be 


\begin{abstract}
Unilateral Spatial Neglect, the most dramatic manifestation of contralesional space unawareness, is a highly heterogeneous syndrome. The presence of neglect is related to core spatially lateralized deficits, but its severity is also modulated by several domain-general factors (such as alertness or sustained attention) and by task demands. We previously showed that a computer-based dual-task paradigm exploiting both lateralized and non-lateralized factors (i.e., attentional load/multitasking) better captures this complex scenario and exacerbates deficits for the contralesional space after right hemisphere damage. Here we asked whether multitasking would reveal contralesional spatial disorders in chronic left-hemisphere damaged (LHD) stroke patients, a population in which impaired spatial processing is thought to be uncommon. Ten consecutive LHD patients with no signs of right-sided neglect at standard neuropsychological testing performed a computerized spatial monitoring task with and without concurrent secondary tasks (i.e., multitasking). Severe contralesional (right) space unawareness emerged in most patients under attentional load in both the visual and auditory modalities. Multitasking affected the detection of contralesional stimuli both when presented concurrently with an ipsilesional one (i.e., extinction for bilateral targets) and when presented in isolation (i.e., left neglect for right-sided targets). No spatial bias emerged in a control group of healthy elderly participants, who performed at ceiling, as well as in a second control group composed of patients with Mild Cognitive Impairment. We conclude that the pathological spatial bias in LHD patients cannot be attributed to a global reduction of cognitive resources but it is the consequence of unilateral brain damage. Clinical and theoretical implications of the loaddependent lack of awareness for contralesional hemispace following LHD are discussed.
\end{abstract}




\subsection{INTRODUCTION}

Unilateral Spatial Neglect (USN) is a key phenomenon for the study of spatial-attentional mechanisms within a neuropsychological framework (Halligan, Fink, Marshall, \& Vallar, 2003; Vallar, 1998). USN is a frequent consequence of stroke and it is commonly defined as the failure to report, respond to or orient towards stimuli in contralesional space, when this failure cannot be attributed to sensory or motor deficits (Driver \& Vuilleumier, 2001; Heilman, Watson, \& Valenstein, 1985). The typical form of USN affects the left side of space as a consequence of right-hemisphere lesions involving one or more areas within a broad cortical and subcortical network subserving spatial cognition and attention (Corbetta \& Shulman, 2011; Molenberghs, Sale, \& Mattingley, 2012). Functional-anatomical mapping of USN symptoms onto specific brain lesions has sparked controversies (e.g., Mort et al., 2003), but contrasting findings can in part be attributed to the heterogeneity of the patients (Halligan et al., 2003). For example, differences related to the location of vascular insult (e.g., middle vs. posterior cerebral artery; Chechlacz, Terry, et al., 2013), time from lesion (Corbetta, Kincade, Lewis, Snyder, \& Sapir, 2005; Karnath, Rennig, Johannsen, \& Rorden, 2011), or spatial reference frame affected by USN (e.g., ego- vs object-centred, personal vs extra-personal, etc.; Chechlacz, Rotshtein, \& Humphreys, 2012; Committeri et al., 2007) might also be characterized by different neural substrates. Another prominent debate in the USN literature revolves around the issue of hemispheric asymmetries in space coding and/or attention networks to explain the "classic" notion that USN following left-sided lesions is common in the acute phase (Stone, Halligan, \& Greenwood, 1993) but it becomes uncommon in the post-acute phase (e.g., affecting less than $5 \%$ of the left brain damaged patients at three months from lesion onset, Ringman, Saver, Woolson, Clarke, \& Adams, 2004; Weintraub \& Mesulam, 1987).

The heterogeneity of USN, with its variety of behavioural manifestations (Azouvi et al., 2002; Halligan et al., 2003) is further increased by "non-spatial" factors that are known to strongly modulate the severity of the spatial deficits (for reviews see Bonato, 2012; Husain \& Rorden, 2003). These factors include alertness (Robertson, Mattingley, Rorden, \& Driver, 1998; Thimm, Fink, Küst, Karbe, \& Sturm, 2006), sustained attention (Robertson et al., 1997; Robertson, Tegnér, Tham, Lo, \& Nimmo-smith, 2008), increased perceptual demands (Aglioti, Smania, Barbieri, \& Corbetta, 1997; Kaplan et al., 1991; Rapcsak, Verfaellie, Fleet, \& Heilman, 1989), and, most relevant for the present study, increased attentional load generated by multitasking (Bonato, Priftis, Umiltà, \& Zorzi, 2013; Bonato, Priftis, Marenzi, Umiltà, \& Zorzi, 2010, 2012; Robertson \& Frasca, 1991; Sarri, Greenwood, Kalra, \& Driver, 2009). It is therefore not surprising that diagnostic tests for USN have markedly different psychometric properties, such as sensitivity and specificity to USN (Azouvi et al., 2002; Ferber \& Karnath, 2001).

Bonato and colleagues (2010) recently proposed a computer-based paradigm in which patients have to perform a spatial monitoring task resembling the double simultaneous stimulation (DSS) test (e.g., Làdavas, 1990), with and without a concurrent task increasing attentional load. 
DSS consists in reporting the position of appearance of visually presented lateralized stimuli (e.g., a rapid flick of the index finger) that are presented on the left, on the right, or on both sides of central fixation (e.g., the nose of the experimenter). Once visual deficits have been excluded, the signature of USN in DSS is an asymmetry between right- and left-sided detections, given that patients with USN tend to ignore targets appearing in the contralesional side of space. Sometimes the failure in reporting a contralesional stimulus occurs only after bilateral target presentation, a deficit called contralesional visual extinction that is conceptualized either as an independent disorder or as a milder form of USN (Driver \& Vuilleumier, 2001). The paradigm of Bonato et al. (2010) employed multitasking to implement a top-down manipulation of attentional load (in either the visual or auditory modality), without any change of the sensory stimulation.

In the studies of Bonato et al. $(2010,2013)$ the load/multitasking condition proved to be extremely sensitive to subtle lateralized disorders in chronic right hemisphere damaged (RHD) patients performing at ceiling in standard paper-and-pencil tasks. For many RHD patients the additional task demands (mimicking an ecological situation in which people have to simultaneously process different sources of information) induced a strong rightward bias that selectively affected contralesional target detection. The same multitasking paradigm administered to young healthy participants did not induce a spatial bias, but attentional load modulated an early ERP component (P1) - and deactivated the primary visual areas regardless of the sensory modality relevant for the secondary task (i.e., visual or auditory) (Bonato, Spironelli, Lisi, Priftis, \& Zorzi, 2015). This is coherent with the vast neuroimaging literature pointing to the existence of early, sensory bottlenecks in information processing - mainly related to short-term memory limits within each modality (Linden, 2007; Marois \& Ivanoff, 2005) - and a more general, amodal fronto-parietal network acting as a central information relay and sensibly limiting our efficiency in multitasking (Dux, Ivanoff, Asplund, \& Marois, 2006; Spence, 2008; Tombu et al., 2011). Nevertheless, these domain-general, non-lateralized factors (which are also relevant for the notion of cognitive resources/reserve; Stern, 2002) are thought to be associated with right-hemisphere mechanisms (Corbetta \& Shulman, 2011; Robertson, 2014).

The present study aims to further demonstrate that multitasking is a convenient tool to investigate the interaction between lateralized and non-lateralized attention mechanisms, thereby allowing the investigation of imbalances in spatial processing that cannot be detected by classic paper-and-pencil tests. In particular, we asked whether our dual-task paradigm would induce attentional asymmetries in patients with chronic left-hemisphere damage (hereafter LHD), that is in a clinical population where contralesional spatial-attentional disorders are uncommon (Ringman et al., 2004). It is currently unknown whether LHD patients would show sensitivity to attentional load, thereby paralleling our previous findings on RHD patients, or whether the sparing of rightlateralized mechanisms allows patients to fully compensate for any spatial / attentional deficit. We report below the results of the dual-task paradigm administered to an unselected, consecutive 
sample of 10 LHD patients, analyzed both at the group level and at the single patient level. The paradigm was also administered to a control group of healthy elderly participants. Moreover, given that healthy individuals typically perform at ceiling in this task (Bonato et al., 2010; Bonato et al., 2015; Lisi, Bonato, \& Zorzi, 2015), we included a second control group of 8 patients diagnosed with Mild Cognitive Impairment $(\mathrm{MCl})$ - a syndrome yielding diffuse cognitive deficits (taking into account individual age and education, Petersen, 2004). $\mathrm{MCl}$ patients can show a subtle spatial bias (either left or right in individual patients) in conditions with bilaterally presented stimuli (Redel et al., 2012). Thus, the higher variability of $\mathrm{MCl}$ patients (with respect to healthy individuals) provides a stringent baseline to assess the reliability of lateralized spatial deficits in LHD patients and it also allows to disentangle spatial bias from the effect of unspecific reduction of cognitive resources.

\subsection{METHODS}

\subsection{Participants}

Ten consecutive stroke patients with LHD took part in the study. They were all admitted to the San Camillo Neurorehabilitation Hospital (Venice-Lido, Italy) to undergo motor rehabilitation for right hemiplegia/hemiparesis and/or language therapy for aphasia. All patients were in the subacute to chronic stage (minimum time from onset: 52 days, see Tab. 1). The first control group included 10 healthy participants, who were on average older than LHD patients $(65.8 \mathrm{y}, \mathrm{SD}=8.52$ for Controls vs. $53.2 \mathrm{y}, \mathrm{SD}=11.7$ for $\mathrm{LHD} ; t(16.44)=2.75, \mathrm{p}=0.014$; Welch's $\mathrm{t}$-test was used for this and the following comparisons) but did not differ for level of education (9.3 y, SD=5.2 for Controls vs 12.4 $y, S D=2.99$ for LHD; $t(14.38)=1.64, p=0.12)$. The second control group was composed by eight outpatients having diagnosis of $\mathrm{MCl}$, who were attending cognitive stimulation protocols at San Camillo Hospital. $\mathrm{MCl}$ patients were also on average older than LHD patients $(69 \mathrm{y}, \mathrm{SD}=11.61$; $\left.t_{(15.2)}=2.85, p=0.012\right)$ but did not differ from LHD for number of years of education (9.75 $\mathrm{y}, \mathrm{SD}=$ $\left.4.02 ; t_{(12.62)}=1.55, p=0.145\right)$. All participants gave written informed consent to take part in the study, in accordance to the principles of the Declaration of Helsinki. Exclusion criteria were the inability to understand task instructions, a history of other neurologic diseases or of substance abuse. All participants were right-handed according to a standard questionnaire (Oldfield, 1971), and presented normal or corrected-to-normal vision. Detailed information is provided in Tab. 1 for personal data and in Tab. 2 for neuropsychological assessment.

Brain lesions for all LHD patients were manually reconstructed using MRIcron (Rorden \& Brett, 2000). Individual scans (MRI or CT) were reoriented using SPM (Friston, Ashburner, Kiebel, Nichols \& Penny, 2007) and then normalized to an age-appropriate template brain by means of the SPM Clinical Toolbox (Rorden, Bonilha, Fridriksson, Bender, \& Karnath, 2012) using enantiomorphic normalization (Nachev, Coulthard, Jäger, Kennard, \& Husain, 2008). Lesion 
overlays are depicted in Fig. 1. The maximal overlap (seven patients) occurred in the white matter between the lateral ventricle and the superior end of the insula (MNI $X=-30, Y-21$ to $-7, Z=20$ ).

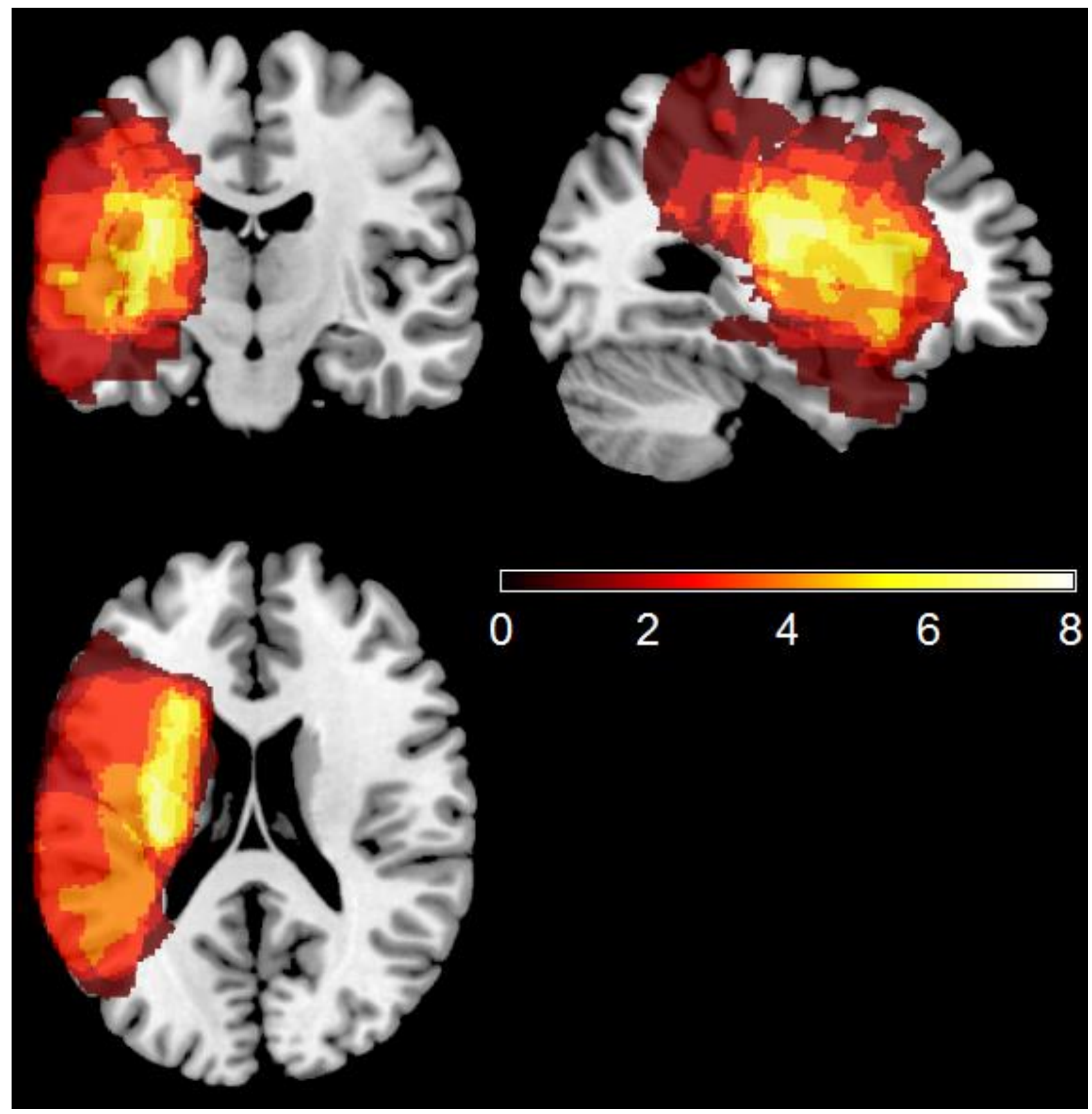

Fig. 1. Lesion overlays. The lesion mapping for LHD, normalized to a template of aged healthy individuals according to the procedure described in Rorden et al. (2012), is shown as an overlay on a standard template using MRIcron (Rorden \& Brett, 2000). The different colors code for the number of overlapping lesions from dark red (minimal/no overlap) to white (maximal overlap). 


\subsection{Neuropsychological Assessment}

All patients underwent an in-depth neuropsychological evaluation (Tab. 2). In the LHD group, the conventional part of the Behavioural Inattention Test (BIT, Wilson, Cockburn, \& Halligan, 1987) was administered in order to assess visuo-spatial functions. The BIT includes six subtests (lines, letters, and stars cancellation, line bisection, figure copy and spontaneous drawing). Each subtest was scored separately, and contributed to a global index. None of the patients in the LHD group showed neglect according to the BIT overall cut-off. Furthermore, no patient was below the cut-off in any of the subtests. No patient showed any hint of lateralized omissions across any subtest; scores in Table 2 are reported separately for right- and left-sided targets. The average, close to ceiling, performance in the cancellation tasks is shown in Fig. 2.

The Aachener Aphasie Test (AAT, Luzzatti, Willmes \& De Bleser, 1996) was administered to quantify presence and degree of language deficits. The results of the comprehension subtest are reported in Tab. 2. All patients were able to comply with task instructions, and provided either a verbal response or pointed towards cardboards depicting all possible answers (see Methods section).

The presence of contralesional omissions/extinction was assessed through the DSS paradigm. The examiner sat in front of the patient, at a distance of about one meter, positioning his hands at the patient's visual periphery. For each trial the experimenter moved either his right or left index finger only, or both fingers simultaneously. The participant had to indicate the side where a movement was perceived. Sixty trials were performed (30 in the upper and 30 in the lower quadrant, and 20 on the right, left, or both sides).

The Rey-Osterrieth complex figure test (Caffarra, Vezzadini, Dieci, Zonato, \& Venneri, 2014) was administered to broadly evaluate a range of visuo-spatial abilities such as planning, organizational, and strategic abilities together with visuo-perceptual and visuoconstructional functions. Both online copy and recall were assessed, and scored separately by summing the number of elements correctly reported weighted by their recall frequency (Caffarra, Vezzadini, Dieci, Zonato, \& Venneri, 2014). The Mini Mental State Examination (MMSE; Magni, Binetti, Bianchetti, Rozzini, \& Trabucchi, 1996) and Raven's progressive matrices (Carlesimo, Caltagirone \& Gainotti, 1996) were also administered to investigate overall cognitive functioning. The MMSE explores patients' spatial and temporal orientation, but also allows a rough evaluation of visuoconstructional abilities, working memory and long term memory; each subpart is scored separately, but a cumulative index is eventually obtained (Magni, Binetti, Bianchetti, Rozzini, \& Trabucchi, 1996). Raven's test comprised 36 coloured matrices; patients had no time constraints, and were asked to choose, among 6 elements, the best option to complete an above-depicted target set. Items were ordered in ascending difficulty order; the overall number of correct responses was scored. This test is thought to assess abstract, relatively culture-free non-verbal reasoning abilities. These last three tests were also part of the neuropsychological assessment of the control group of 
$\mathrm{MCl}$ patients. The diagnosis of $\mathrm{MCl}$ was made accordingly to Petersen (2004) criteria. All patients complained about cognitive deficits in everyday life, and at least one relative of each patient supported this complaint. Global cognitive functioning, as assessed through MMSE and Raven's matrices (therefore including orientation in space/time and abstract reasoning), was spared (see Tab. 2), whereas they showed a deficitary performance in at least one task within a standardized screening battery assessing a broader range of cognitive functions.

\begin{tabular}{|c|c|c|c|c|c|c|}
\hline Subject/Group & $\begin{array}{c}\text { Sex/Age/Education } \\
\text { (ys) }\end{array}$ & Etiology & Handedness & $\begin{array}{c}\text { Double } \\
\text { Simultaneous } \\
\text { Stimulation }\end{array}$ & $\begin{array}{l}\text { Lesional } \\
\text { Volume } \\
\text { (cc) }\end{array}$ & $\begin{array}{l}\text { Time from } \\
\text { stroke } \\
\text { (days) }\end{array}$ \\
\hline 1/LHD & $\mathrm{M} / 46 / 11$ & $\mathrm{H}$ & $\mathrm{R}$ & - & 27 & 115 \\
\hline 2/LHD & $\mathrm{F} / 49 / 13$ & $\mathrm{H}$ & $R$ & - & 15 & 318 \\
\hline 3/LHD & $\mathrm{M} / 60 / 13$ & $\mathrm{H}$ & $\mathrm{R}$ & - & 5 & 2632 \\
\hline 4/LHD & $F / 53 / 13$ & $\mathrm{H}$ & $\mathrm{R}$ & - & 79 & 299 \\
\hline 5/LHD & $\mathrm{F} / 52 / 13$ & I & $\mathrm{R}$ & - & 246 & 145 \\
\hline 6/LHD & $\mathrm{M} / 47 / 13$ & $\mathrm{H}$ & $\mathrm{R}$ & - & 79 & 52 \\
\hline 7/LHD & $\mathrm{M} / 64 / 17$ & $\mathrm{I}$ & $\mathrm{R}$ & - & 165 & 370 \\
\hline 8/LHD & $\mathrm{M} / 41 / 13$ & $\mathrm{I}$ & $\mathrm{R}$ & - & 46 & 313 \\
\hline 9/LHD & $\mathrm{F} / 41 / 13$ & $\mathrm{H}$ & $R$ & $\begin{array}{c}+ \text { (Contralesional } \\
\text { omissions) }\end{array}$ & 136 & 260 \\
\hline 10/LHD & $\mathrm{M} / 79 / 5$ & $\mathrm{H}$ & $\mathrm{R}$ & - & 1 & 57 \\
\hline $1 / \mathrm{MCl}$ & $\mathrm{M} / 56 / 17$ & & $\mathrm{R}$ & & & \\
\hline $2 / \mathrm{MCl}$ & $\mathrm{M} / 49 / 11$ & & $\mathrm{R}$ & & & \\
\hline $3 / \mathrm{MCl}$ & $\mathrm{M} / 84 / 8$ & & $\mathrm{R}$ & & & \\
\hline $4 / \mathrm{MCl}$ & $\mathrm{F} / 73 / 9$ & & $\mathrm{R}$ & & & \\
\hline $5 / \mathrm{MCl}$ & $\mathrm{M} / 72 / 10$ & & $\mathrm{R}$ & & & \\
\hline $6 / \mathrm{MCl}$ & $\mathrm{F} / 73 / 5$ & & $\mathrm{R}$ & & & \\
\hline $7 / \mathrm{MCl}$ & $\mathrm{F} / 79 / 5$ & & $\mathrm{R}$ & & & \\
\hline $8 / \mathrm{MCl}$ & $\mathrm{M} / 66 / 13$ & & $\mathrm{R}$ & & & \\
\hline
\end{tabular}

Tab. 1 Demographical and neurological data. LHD and $\mathrm{MCl}$ groups: M/F: male, female; R: Right-handed. LHD: $\mathrm{l} / \mathrm{H}$ : ischemic, hemorrhagic; +/-: presence, absence of contralesional omissions. 


\begin{tabular}{|c|c|c|c|c|c|c|c|c|}
\hline Subject/Group & $\begin{array}{c}\text { MMSE } \\
\text { (Cut- } \\
\text { off: 24) }\end{array}$ & \begin{tabular}{|c|} 
RAVEN \\
(Cut- \\
off: \\
$18.96)$ \\
\end{tabular} & \begin{tabular}{|c|} 
Rey-Osterrieth \\
complex figure- \\
Copy/Recall \\
(Cut-off: \\
$28.87 / 9.46$ )
\end{tabular} & $\begin{array}{c}\text { BIT } \\
\text { (Cut-off: } \\
<130 \text { ) }\end{array}$ & $\begin{array}{c}\text { BIT- } \\
\text { Barrage- } \\
\text { Left/Right } \\
\text { Targets } \\
\text { cancelled } \\
\text { (max } \\
18 / 18 \text { ) }\end{array}$ & $\begin{array}{c}\text { BIT-Star } \\
\text { Cancellation } \\
\text { Task-Left/Right } \\
\text { Targets } \\
\text { cancelled (max } \\
\text { 27/27) }\end{array}$ & $\begin{array}{l}\text { BIT-Letters } \\
\text { Cancellation } \\
\text { Task-Left/Right } \\
\text { Targets } \\
\text { cancelled (max } \\
\text { 20/20) }\end{array}$ & $\begin{array}{c}\text { AAT - } \\
\text { Comprehension }\end{array}$ \\
\hline 1/LHD & 30 & 30.8 & $34.75 / 16$ & 142 & $18 / 18$ & $27 / 27$ & $20 / 18$ & 9 \\
\hline 2/LHD & 27.9 & 31.8 & $35.25 / 19.75$ & 146 & $18 / 18$ & $27 / 27$ & $20 / 20$ & 9 \\
\hline 3/LHD & 27.5 & 29.8 & $27.25^{\star} / 13.75$ & 138 & $18 / 18$ & $25 / 26$ & $20 / 20$ & 8 \\
\hline 4/LHD & n.a. & 25.3 & $26.75^{\star} / 12.75$ & 144 & $18 / 18$ & $27 / 27$ & $20 / 20$ & 6 \\
\hline 5/LHD & n.a. & 32.8 & $35.25 / 14.75$ & 140 & $18 / 16$ & $27 / 27$ & $19 / 18$ & 4 \\
\hline 6/LHD & 24.9 & 26.3 & $33 / 6.5^{*}$ & 136 & $18 / 18$ & $26 / 27$ & $16 / 16$ & $2^{*}$ \\
\hline 7/LHD & n.a. & 22.6 & $32 / 22.75$ & 145 & $18 / 18$ & $27 / 27$ & $20 / 20$ & 7 \\
\hline 8/LHD & 25.9 & 31.8 & $32.5 / 24$ & 145 & $18 / 18$ & $27 / 27$ & $20 / 19$ & 9 \\
\hline 9/LHD & n.a. & 30.8 & $31.5 / 7^{*}$ & 145 & $18 / 18$ & $27 / 27$ & $20 / 20$ & 4 \\
\hline 10/LHD & $20.7^{*}$ & 19 & $7.75^{\star} / 8.75^{\star}$ & 132 & $17 / 18$ & $27 / 27$ & $16 / 18$ & - \\
\hline $1 / \mathrm{MCl}$ & 27 & 31.6 & $36 / 2.75^{*}$ & & & & & \\
\hline $2 / \mathrm{MCl}$ & 27 & 33.1 & $38.75 / 14.75$ & & & & & \\
\hline $3 / \mathrm{MCl}$ & 26.7 & 29.1 & $26.75^{\star} / 8.75^{\star}$ & & & & & \\
\hline $4 / \mathrm{MCl}$ & 25.4 & 27.3 & $26.25^{\star} / 15.25$ & & & & & \\
\hline $5 / \mathrm{MCl}$ & 25.4 & 34.6 & $38 / 18.75$ & & & & & \\
\hline $6 / \mathrm{MCl}$ & 25.3 & 27.2 & $28.75^{\star} / 15.75$ & & & & & \\
\hline $7 / \mathrm{MCl}$ & $21.7^{*}$ & 33 & $28.75 * / 13.25$ & & & & & \\
\hline $8 / \mathrm{MCl}$ & 26.2 & 33.4 & $34.75 / 11$ & & & & & \\
\hline
\end{tabular}

Tab. 2. Neuropsychological assessment. MMSE (Mini Mental State Examination, Magni et al., 1996), Raven's progressive matrices (Carlesimo et al., 1996), and Rey-Osterrieth complex figure (Copy and Recall, Caffarra, Vezzadini, Dieci, Zonato, \& Venneri, 2014). Across all tasks, age and education corrected scores are reported. *: performance below cut-off. BIT (Behavioural Inattention Test, Wilson, Cockburn, \& Halligan, 1987): global scores and raw scores at cancellation subtests are reported separately for left and right hemispace. AAT (Aachener Aphasie Test, Luzzatti, Willmes \& De Bleser, 1996): results from the comprehension subtest are reported, classified according to a standard nine points scale (lower values index a more severe deficit). -: data not available. n.a.: unable to assess. 


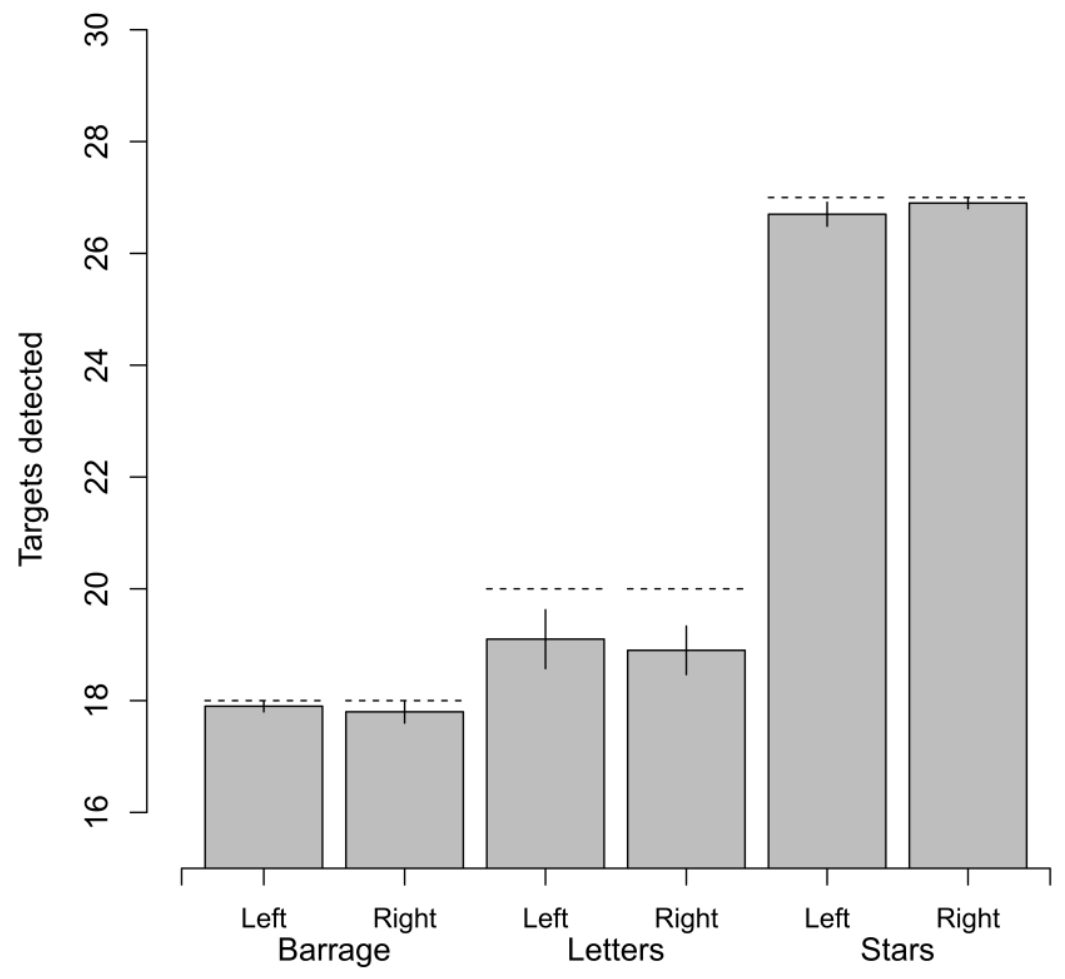

Fig. 2. Cancellation tasks. The mean number of target items correctly detected is shown for each BIT cancellation subtest as a function of their side on the testing sheet. Dashed lines represent the total number of targets for the specific subtest. Error bars represent SEM.

\subsection{Apparatus, stimuli, and procedures}

Patients were individually tested in a quiet room, sitting comfortably at a distance of about $60 \mathrm{~cm}$ from a 19-inch computer monitor. There were three experimental conditions: the single-task condition and two dual-task conditions (visual vs. auditory). Each trial started with a black screen (1000 ms), followed by a white fixation cross (about $1 \mathrm{~cm}$ wide) that was presented in the center of the screen for $800 \mathrm{~ms}$. The fixation cross flickered for $200 \mathrm{~ms}$ before target presentation as a warning signal and to redirect overt attention to the screen center. The lateralized visuospatial target was a white disk (diameter: $8 \mathrm{~mm}$ ) presented against a black background for a duration of $100 \mathrm{~ms}$. The target could appear unilaterally, on the left or the right side of the display (lateral distance from fixation: $170 \mathrm{~mm}$ ), or bilaterally (both on the left- and on the right side). "Catch" trials, in which no target was actually displayed on the screen, were also included to assess a potential spatial bias in responses. The three target locations (left, right, bilateral) and the catch trials were equiprobable (i.e., $25 \%$ of each type) and presented in random order. Simultaneously with the lateralized target(s) and for the same duration (100 ms), a visual shape (a line drawing chosen randomly among triangle, square and circle) was shown at fixation and a sound (an environmental 
sound chosen randomly among train whistle, doorbell, and hammer) was presented through binaural earphones. Once the $100 \mathrm{~ms}$ time window elapsed, a noisy screenshot was presented until the beginning of the following trial, as to minimize retinal after-image.

Patients always had to report the position of the target(s) (i.e., "no target", "right", "left", or "both" sides) as first response. This was the only request for the single task condition, whereas in the dual-visual or dual-auditory conditions they also had to report the central shape or the presented sound, respectively. It is worth to emphasize that the sensory stimulation was identical across the three conditions. The manipulation was therefore purely top-down, based on the presence/absence of concurrent task demands. In order to facilitate patients with difficulties in naming, responses were provided either verbally and/or by pointing to an ad-hoc cardboard depicting all possible answers. Patients' responses were then coded by the experimenter using a computer keyboard.

Participants were allowed to rest after each trial, if necessary. The experimenter monitored eye movements and started each trial only when fixation was maintained. Trials affected by eye movements were marked and discarded offline in the data analyses. The experiment was divided in 6 blocks, each condition (single, auditory, or visual) being repeated twice (i.e., two blocks per condition). The single task condition was administered in the first and in the last block in order to assess the potential effects of fatigue or sustained attention problems. Accordingly, the dual task conditions were performed in blocks 2 to 5 - with a fixed alternating order (i.e., visual-auditoryvisual-auditory). A practice phase, consisting of 21 trials, was carried out before starting the experiment to allow patients familiarizing with the primary task. During this phase the experimenter repeatedly ensured that the patient fully understood task requirements. Each block comprised 36 trials ( 9 trials for each type of lateral target). All possible combinations of shapes (3) and sounds (3) were presented within each block, balanced in frequency and with randomized order. Overall, the experiment consisted of 216 trials ( 3 load conditions $x 4$ types of target $x 18$ trials per cell).

\subsection{Statistical analyses}

Data were analyzed with the open-source software $R$ ( $R$ Core Team, 2015). Practice trials and experimental trials invalidated by eye movements $(<0.1 \%)$ were discarded. When appropriate, we analyzed the data at the single-trial level with mixed-effects multiple regression models (Baayen, Davidson, \& Bates, 2008) using the Ime4 package for $\mathrm{R}$ (Bates, Maechler, Bolker, \& Walker, 2014). A main advantage of mixed models, in addition to the use of single trial (rather than averaged) data, is that they do not assume independence amongst observations, and the model fitting procedure takes into account the covariance structure of the data, including random effects (i.e., individual variability). This approach is particularly interesting for the analysis of clinical data, which are typically more noisy than the data of healthy participants (see Zorzi et al., 2012, for a 
previous application of mixed models to neglect patients' data; also see Goedert, Boston, \& Barrett, 2013).

All mixed-effects models had a logistic link-function, which is appropriate for a dependent variable with binary distribution (i.e., accuracy). As a first step we defined a model containing the random effects. Linear mixed models generalize best by including the maximum random structure that does not prevent model convergence (Bates, Kliegl, Vasishth, \& Baayen, 2015). Random intercepts and random slopes were introduced sequentially and their effect on model fit was assessed using a log-likelihood test (that is, we compared the residuals of each model and choose the one with significantly lower deviance as assessed by a chi squared test). The model with the final random effects structure was then used to introduce the fixed effects. We used a stepwise approach, adding main effects before interactions, and used the same log-likelihood tests to assess whether the improvements in the model fit were statistically significant.

\subsection{RESULTS}

The Results section is organized as follows. First, we report analyses of spatial monitoring accuracy to assess whether performance is modulated by target position and by attentional load. Second, we report in-depth analyses of spatial bias, which was assessed for LHD patients both at the group and at the single-case levels. Finally, we report additional analyses of spatial monitoring accuracy that assessed potential effects of fatigue, or deficit in sustained attention.

\subsection{Effects of Attentional load on spatial monitoring}

As a preliminary analysis we ran an omnibus ANOVA with Target Type (Left, Right, Bilateral, Catch) and Load condition (i.e., Single Task, Visual Dual Task, Auditory Dual Task) as withinsubjects factors and Group (LHD, Controls, MCl) as between-subjects factor. The accuracy was arcsine transformed. This analysis showed a significant three-way interaction Group by Type by Load $(F(12,150)=2.2, p=0.026$, Greenhouse-Geisser corrected, $n p 2=0.15)$. The accuracy data, plotted in Figure 3, suggest that the multitasking conditions selectively affected performance for bilateral and right-sided targets, but only for LHD patients. We therefore fitted mixed-effects models to the (non-transformed, single-trial) accuracy data of each group to assess the interactive effects of Target Type and Load. The random structure included Participant as random intercept and the random slopes for Load and Target type. In other words, individual variability was accounted for both in terms of overall accuracy (intercept) and across the different experimental conditions (random slopes).

LHD. Neither of the fixed main effects was found to significantly improve the model fit (Load: $X^{2}=$ 2.27, $p=0.32$; Target type: $X^{2}=3.35, p=0.34$ ). Crucially for our hypotheses, however, the Load by Target type interaction improved model fit $\left(X^{2}=26.38, p<0.001\right)$. Notably, for bilateral trials 
detection accuracy under load dropped from $80.4 \%$ to $65 \%$ for auditory load $(z=-2.67, p=0.007$ ) and to $58.9 \%$ for visual load $(z=-4, p<0.001)$, with a significant difference also emerging between visual and auditory $(z=-2.16, p=0.03)$. For contralesional (i.e., right only) targets accuracy dropped from $92.2 \%$ to $69.1 \%$ for auditory load $(z=-3.3, p<0.001)$ and to $62 \%$ for visual load $(z=-4.6, p<$ $0.001)$, with a significant difference emerging also between the two dual task conditions $(z=-2.24$, $p=0.025)$. All the contrasts above report the Wald $z$ value with uncorrected $p$ value. Performance for ipsilesional targets and catch trials remained high (>96.1\%) and it was not modulated by load condition. The parameters of the random and fixed effects of the final model are reported in Tab. 3. Healthy Controls. Neither of the fixed main effects improved the model fit (Load: $X^{2}=5.32, p=0.07$; Target type: $\left.X^{2}=2.9, p=0.4\right)$. The fit did not improve when adding the two-way interaction $\left(X^{2}=\right.$ $6.63, p=0.36$ ). Indeed, accuracy remained high across conditions.

$\mathrm{MCl}$. Neither of the fixed main effects improved the model fit (Load: $X^{2}=2.39, p=0.3$; Target type: $\left.X^{2}=2.65, p=0.45\right)$. Moreover, the fit did not improve when adding the two-way interaction $\left(X^{2}=\right.$ $4.04, p=0.67$ ) indexing that accuracy remained high across load conditions.

To summarize, we found that multitasking induced a selective impairment in detecting bilateral and contralesional targets in LHD, whereas the performance of healthy controls and $\mathrm{MCl}$ patients was unaffected. We therefore proceeded to investigate how errors were spatially distributed across conditions. 

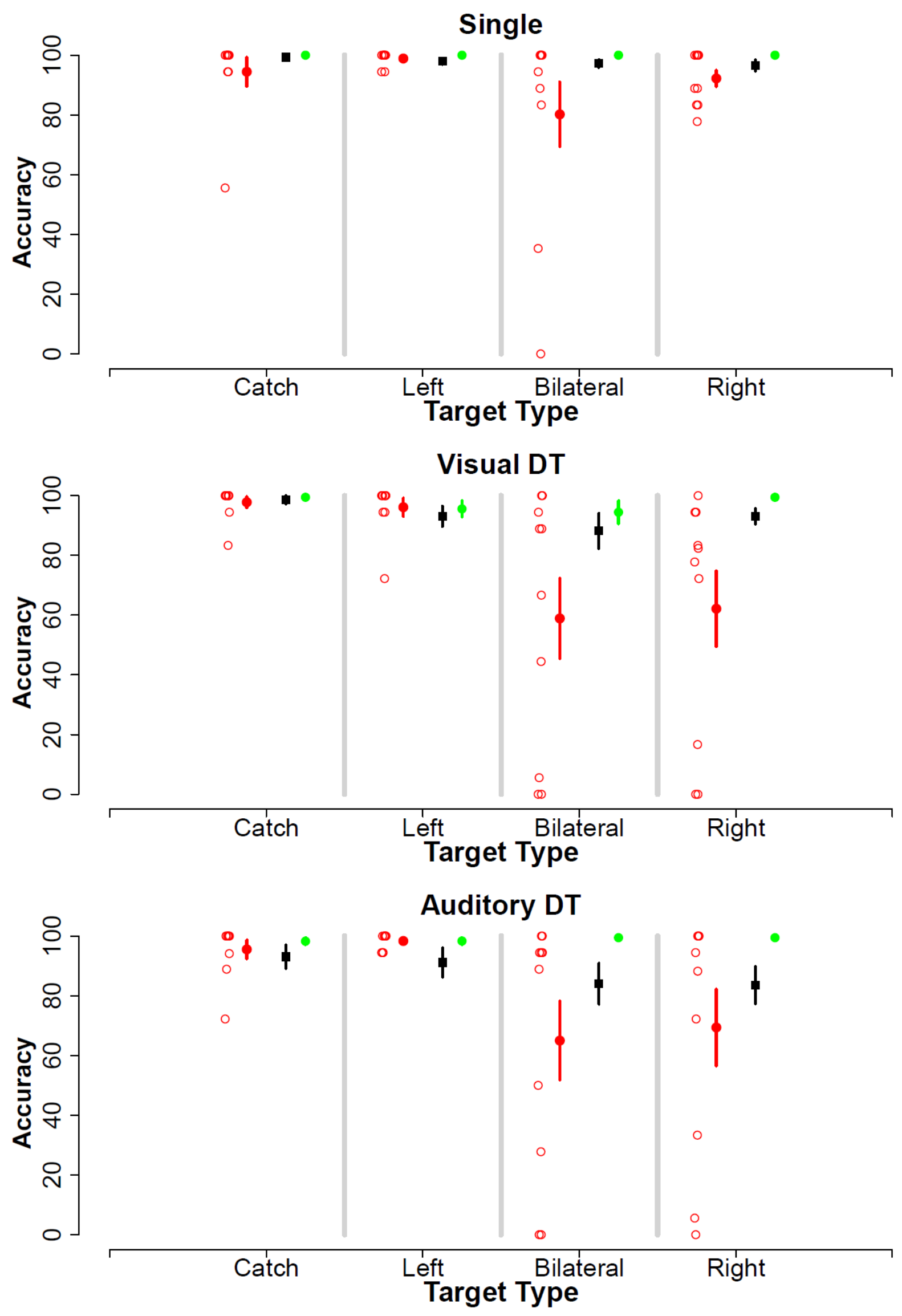
Fig. 3. Spatial monitoring task: global accuracy. Accuracy in the spatial monitoring task is depicted for each Load condition (single task, visual dual task, auditory dual task) as a function of Target type (left, right, bilateral, catch) and Group (LHD: filled red circles; MCl: black squares; Healthy Controls: green circles). Error bars represent SEM. Individual performance of LHD patients is shown using red empty circles.

\begin{tabular}{|c|c|c|c|c|c|c|c|c|}
\hline \multicolumn{9}{|c|}{ Random effects: } \\
\hline Groups & Name & Variance & SD. & Corr. & & & & \\
\hline \multirow[t]{6}{*}{ Subject } & (Intercept) & 2.46 & 1.57 & & & & & \\
\hline & Side - Bilateral & 7.15 & 2.6 & 0.01 & & & & \\
\hline & Side - Catch & 0.25 & 0.5 & 0.22 & -0.3 & & & \\
\hline & Side - Right & 2.6 & 1.6 & -0.33 & 0.72 & -0.82 & & \\
\hline & Load - Auditory & 0.76 & 0.88 & 0.16 & 0.25 & -0.92 & 0.66 & \\
\hline & Load - Visual & 1 & 1 & -0.33 & 0.33 & -0.99 & 0.86 & 0.86 \\
\hline \multicolumn{2}{|c|}{ Fixed effects: } & Estimate & SE & $z$ value & $\mathbf{p}$ & & & \\
\hline & (intercept) & 5.52 & 1 & 5.36 & $<0.001^{\star \star \star}$ & & & \\
\hline & Single -Bilateral & -2.38 & 1.3 & -1.83 & 0.07 & & & \\
\hline & Single - catch & -1.55 & 1 & -1.53 & 0.12 & & & \\
\hline & Single - Right & -1.8 & 1.1 & -1.64 & 0.1 & & & \\
\hline & Auditory - Bilateral & -4.3 & 1.4 & -3.13 & $<0.01^{\star *}$ & & & \\
\hline & Auditory - Catch & -1.14 & 1.1 & -1 & 0.31 & & & \\
\hline & Auditory - Right & -3.92 & 1.2 & -3.3 & $<0.001^{* \star *}$ & & & \\
\hline & Auditory - Left & 013 & 1.1 & 0.12 & 0.9 & & & \\
\hline & Visual - Bilateral & -5.23 & 1.4 & -3.78 & $<0.001^{* \star *}$ & & & \\
\hline & Visual - Catch & -0.86 & 1.2 & -0.73 & 0.46 & & & \\
\hline & Visual - Right & -4.81 & 1.2 & -3.9 & $<0.001^{\star \star \star}$ & & & \\
\hline & Visual - Left & -1.29 & 1 & -1.33 & 0.18 & & & \\
\hline
\end{tabular}

Tab. 3. Details of the final mixed-effects model for LHD patients. Factors were dummy coded with left targets in the single task as reference level. The parameters of the random effects are reported in the top panel. The parameters of the fixed effects are reported in the bottom panel. Note that the $b$ coefficient (Estimate) represents the adjustment with respect to the reference level. $\mathrm{SD}=$ standard deviation, $\mathrm{SE}=$ standard error.

\subsection{Asymmetry Indices}

We computed Asymmetry Indices (Al) for unilateral, bilateral and catch trials to investigate whether and how omissions were spatially distributed. The Als for bilateral and catch trials were 
(separately) computed by subtracting, for each individual, the proportion of "left" responses from the proportion of "right" responses. A negative Al indexes that "left" responses prevailed among errors while positive $\mathrm{Al}$ reveals prevalence of "right" responses. For unilateral trials Als were obtained by subtracting the proportion of omissions for right-sided targets from the proportion of omissions for left-sided targets. The resulting index is similar to the previous one, with negative values representing a leftward bias and positive values representing a rightward bias. Note that all Al values express the asymmetry in terms of proportion of errors. That is, a value of -1 indicates that all $(100 \%)$ of the right targets but none $(0 \%)$ of the left targets were missed, whereas a value of 0 indicates that an equal number of left and right targets were missed (or that no targets were missed). For each Al, we first assessed whether it significantly differed from 0 (thereby indexing spatial bias) by means of a one-sample t-test (across all Load conditions). If that was the case, we proceeded with assessing the modulatory effect of attentional Load. Comparisons between groups could not be performed due to striking differences in variance and violation of normality. All results are depicted in Fig. 4.

Unilateral targets. Als significantly differed from 0 in $\operatorname{LHD}\left(t_{(9)}=-2.65, p=0.026\right)$. One-way repeated measures ANOVA showed an effect of Load $\left(F_{(2,18)}=5.06, p=0.018, \eta_{p}{ }^{2}=0.359\right)$, with Al decreasing from -0.06 in the single task to -0.29 in the auditory and -0.3 in the visual task $\left(t_{(9)}>2.43\right.$, $p<0.037)$, but with no differences between the two dual tasks $\left(t_{(9)}=0.24, p=0.82\right)$.

In contrast, Als did not significantly differ from 0 both in the $\mathrm{MCl}$ group $\left(t_{(7)}=-0.84, p=0.43\right)$ and in the Healthy Controls group $\left(t_{(9)}=0.61, p=0.56\right)$.

Bilateral targets. Al were overall negative in $\operatorname{LHD}\left(t_{(9)}=-2.6, p=0.029\right)$. One-way repeated measures ANOVA showed an effect of Load $\left(F_{(2,18)}=5.46, p=0.033\right.$, Greenhouse-Geisser corrected, $\left.\eta_{p}{ }^{2}=0.378\right)$, with Al decreasing from -0.2 in the single task to -0.34 in the auditory $\left(t_{(9)}=\right.$ $2, p=0.071)$ and -0.41 in the visual task $\left(t_{(9)}=2.56, p=0.03\right)$. Auditory and visual dual tasks did not differ $\left(t_{(9)}=2.05, p=0.07\right)$. Als were not significantly different from 0 both in the $\mathrm{MCl}$ group $\left(t_{(7)}=1.5\right.$, $p=0.178)$ and in the Healthy Controls group $\left(t_{(9)}=-1, p=0.34\right)$

Catch trials. Als did not significantly differ from 0 in all groups: $\operatorname{LHD}\left(t_{(9)}=-0.8, p=0.47\right) ; \mathrm{MCl}\left(t_{(7)}=\right.$ 1.87, $p=0.1)$; Controls $\left(t_{(9)}=0.04, p=0.97\right)$. This shows that LHD patients were able to correctly report the absence of lateral targets and it allows to exclude that the asymmetry of responses in unilateral and bilateral trials was due to a response bias (i.e., an overall tendency to respond "left"). 

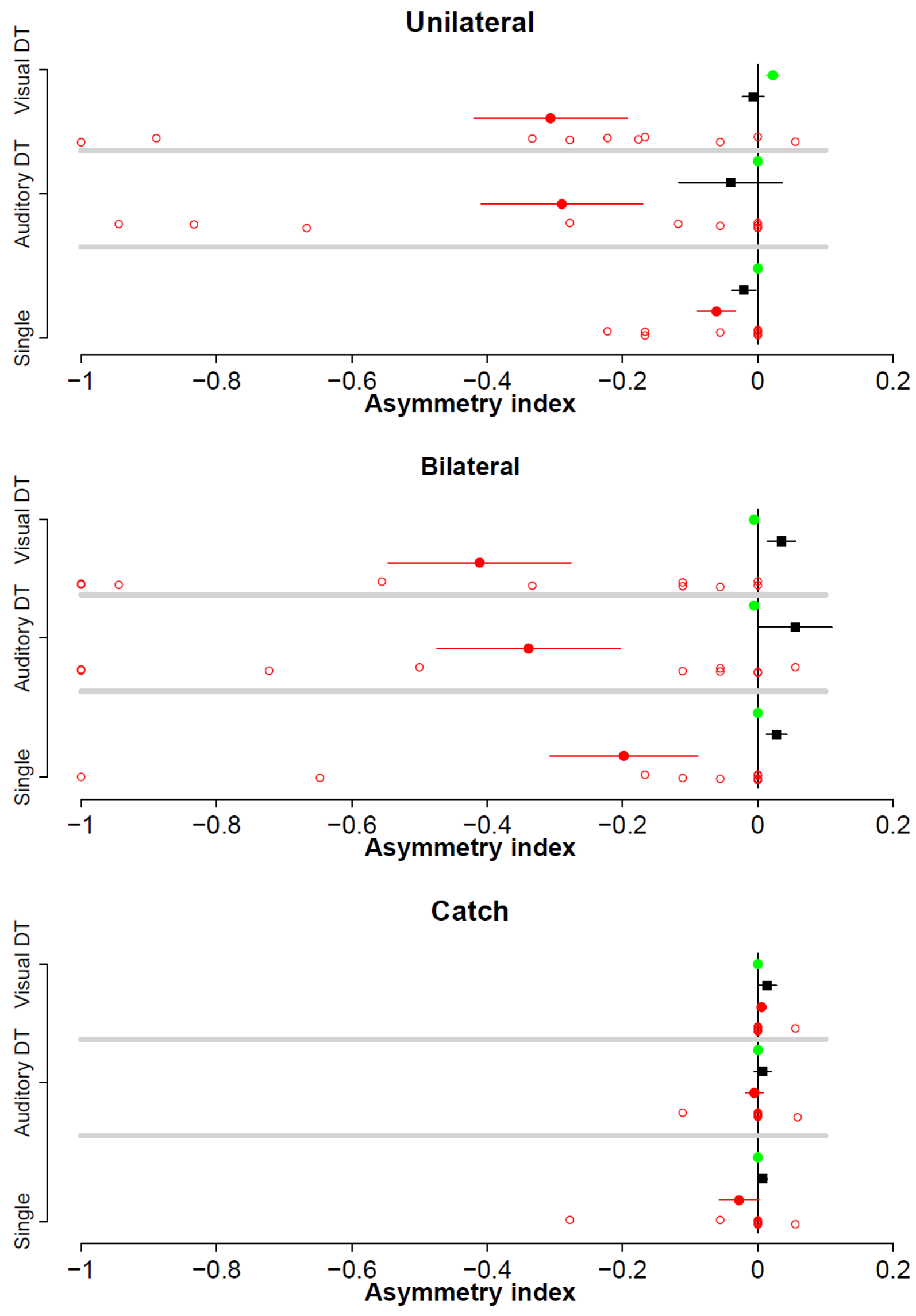
Fig. 4. Lateralized biases. The Asymmetry Index is depicted for each type of target (unilateral, bilateral, catch) as a function of Load condition (single task, visual dual task, auditory dual task) and Group (LHD: red circles; MCl: black squares; Healthy Controls: green circles). Note that the asymmetry is expressed in terms of proportion of errors: negative values index a leftward bias (e.g., a value of -1 means that all of the right but none of the left targets were neglected), whereas a value of 0 indicates even distribution of omissions (or the absence of omissions). Individual values for LHD patients are shown as red empty circles. Error bars represent SEM.

Individual analysis. The group of healthy controls showed ceiling performance in the spatial monitoring task, thereby showing that our paradigm is well-suited to detecting spatial asymmetries caused by unilateral brain damage. However, when controls' data are used to assess the presence of deficit in individual patients, ceiling effects can produce unacceptably high false positive rates (see Laws, 2005). In contrast, the group of $\mathrm{MCl}$ patients is characterized by a much higher variability in performance than the healthy controls. Indeed, Redel et al. (2012) observed subtle spatial bias in individual $\mathrm{MCl}$ patients, though at the group level the direction of bias is inconsistent. Therefore, the $\mathrm{MCl}$ group provides a baseline that is statistically more appropriate as well as more stringent than the one provided by healthy participants (against which almost all LHD patients would have resulted as having a pathological performance).

To determine how many LHD patients presented with a pattern of right neglect in the unilateral trials or extinction in the bilateral trials, we assessed the individual $\mathrm{Al}$ against the $\mathrm{MCl}$ group as control sample using the method proposed by Crawford and Howell (1998). This method uses the control sample statistics (rather than the estimated population parameters), and a $t$ (instead of $z$ ), wider-tailed distribution to estimate probabilities. Note that this approach is robust even in the presence of severe violations of normality (Crawford et al, 2006).

Unilateral trials. Patients 4, 7 and 9 showed significant asymmetry in the single task $(t(7) \leq-2.7, p \leq$ $0.03)$, which persisted in the auditory dual task $(t(7) \leq-2.75, p \leq 0.029)$ and in the visual dual task $(t(7) \leq-6.62, p<0.001)$. Strikingly, the visual dual task induced a spatial bias in four patients with symmetric performance in the single task [patients $2,5,6$, and $8(t(7) \leq-3.25, p \leq 0.014)$ ]. In summary, while only three patients out of ten presented contralesional omissions at baseline, multi-tasking revealed contralesional deficits in additional four cases in the visual dual task condition.

Bilateral targets. Patients 4, 5, 7 and 9 showed a significant asymmetry in the single task $(t(7) \leq-$ $3.12, p \leq 0.017)$. The same patients consistently showed a spatial bias in both the visual $(t(7) \leq-$ 
9.44, $p(s)<0.001)$ and the auditory $(t(7) \leq-3.45, p(s) \leq 0.01)$ dual tasks. Finally, patient 2 presented extinction in the visual dual task only $(t(7)=-5.89, p<0.001)$.

Correlations between $\mathbf{A l}$ and lesional volume. We performed an explorative correlational analysis between Als and lesion volume, though the results must be taken with caution due to the small sample size. When Al for unilateral trials (collapsed across Tasks) were correlated with lesional volume, no significant correlation was found $(r=-0.4, t(8)=1.1, p=0.24)$. When $\mathrm{Al}$ for bilateral trials were analyzed, on the other hand, a significant negative association emerged $(r=-$ $0.72, t(8)=2.96, p=0.018)$. This was due to significant correlations for $A l$ in Visual $(r=-0.75$, $t(8)=3.22, p=0.012)$ and Auditory $(r=-0.79, t(8)=3.7, p=0.006)$ dual-task conditions, as opposed to a lack of correlation in the Single task $(r=-0.496, t(8)=1.61, p=0.14)$. All correlations were two-tailed, uncorrected, and overall suggest that more severe damage (wider lesion) within the left hemisphere results in stronger extinction under attentional load.

\subsection{Fatigue and sustained attention}

We then assessed whether fatigue, or deficit in sustained attention, could partially account for the impaired spatial monitoring performance of LHD patients. Note that the single task was performed both at the beginning (i.e., first block of trials) and at the end (i.e., last block of trials) of the experiment. Therefore, a significant drop in performance between the first and last block would suggest that the effect of multitasking is somewhat confounded with fatigue. A mixed-effects model was fitted to the accuracy data from the single task trials. The random effects matrix included random slopes for Block (first or last) and Target type, in addition to the random intercept for Participant. Note that the group of Healthy Controls was not included in the analysis because their performance in the single task was errorless (100\% accuracy in both blocks).

Notably, Block did not improve model fit when it was entered as fixed main effect $\left(x^{2}=2.82, p=\right.$ 0.09 ) or in the two-way interaction with Group $\left(X^{2}=1.52, p=0.22\right)$. This shows that fatigue (or, conversely, learning) had no effect (see Fig. 5 for a graphical representation). Note that accuracy (collapsed across Target type) slightly dropped in $\mathrm{MCl}$ patients (from $99.3 \%$ to $96.2 \%$ ), but it slightly improved (89.6\% to $93.3 \%$ ) in LHD patients. 

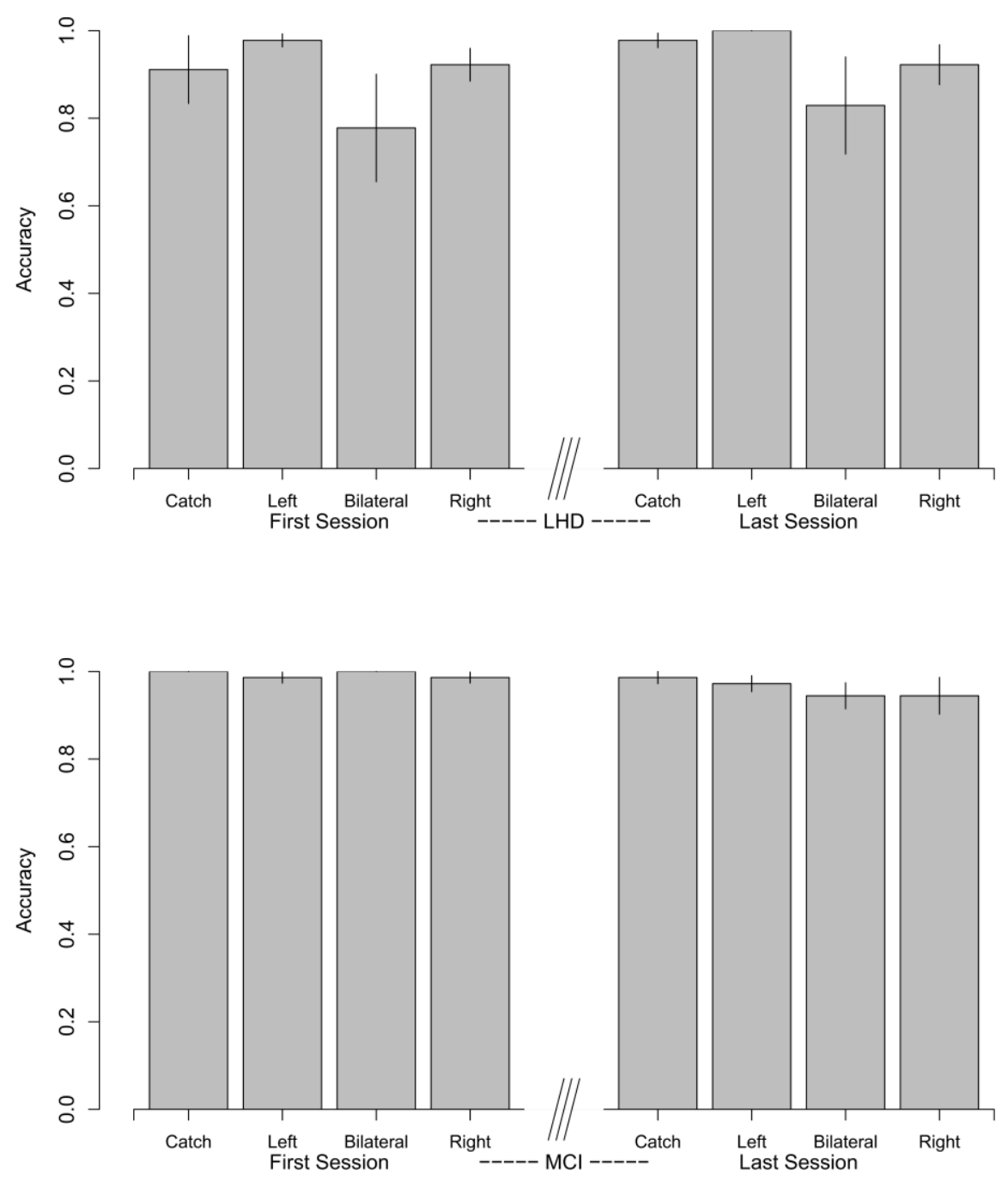

Fig. 5. Fatigue. Performance of LHD (top panel) and $\mathrm{MCl}$ (bottom panel) patients in the first block (four bars on the left) and in the last (i.e., sixth) block of the spatial monitoring task (four bars on the right). In both blocks patients only had to report target side. Error bars represent SEM.

\subsection{Secondary task}

As a final analysis we assessed whether accuracy in the secondary task differed as a function of Type of load (visual vs. auditory) or Group (LHD vs. MCl). Again, note that we did not include the Healthy Controls group because of ceiling performance (97.5\% accuracy in both secondary tasks). A mixed-effects model was fitted to the accuracy data. The random effects structure included random intercept and slope for Type of load, in addition to a random intercept for Participant. When the main effects of Type of load and Group were entered as fixed effects, only the former significantly improved model fit $\left(X^{2}=4.18, p=0.04\right.$ vs. $\left.X^{2}=0.52, p=0.47\right)$. The Group by Type of load interaction did not improve the fit $\left(X^{2}=0.83, p=0.36\right)$. The visual (secondary) task was overall more difficult $(\beta=-1.12, O R=0.325, z=-2.7, p=0.007$ ), resulting in about $76.12 \%$ of correct responses 
against $88.35 \%$ of correct responses for the auditory task, but the two groups of patients did not show reliable differences.

\subsection{DISCUSSION}

We investigated the effects of attentional load (i.e., multitasking) on a spatial monitoring task in a sample of chronic left hemisphere stroke patients, a clinical population in which impaired spatial processing is thought to be uncommon. Concurrent task demands, regardless of the sensory modality of attentional load (visual or auditory), revealed a pattern of contralesional targets omission (right neglect and/or right extinction) despite the absence of any spatial deficit at neuropsychological testing. In contrast, no spatial biases were found in two groups of control participants: healthy elderly participants showed ceiling performance, while patients with Mild Cognitive Impairment performed less well but showed even (unbiased) spatial distribuition of errors.

Overall, the present findings confirm that our multitasking paradigm is well-suited to detect asymmetries in spatial monitoring caused by lateralized bran damage, as previously observed in chronic RHD patients (Bonato et al., 2010). It is worth noting, however, that several changes to the original paradigm of Bonato et al. (2010) have been introduced in the present study to further improve its design and to make it more suitable for testing LHD patients, which are often characterized by linguistic deficits. First, all alphanumerical stimuli were removed, whereas in Bonato and colleagues a letter was visually presented at fixation (to be reported in the visual dual task) and a number-word was auditorily presented (for the auditory dual task). Moreover, the previous version of the auditory dual task required counting forward twice by two from the presented digit, whereas in the present version the request to merely report the auditory stimulus minimized the demands on working memory. Second, the spatial monitoring task was prioritized over the concurrent task by asking patients to always report the lateralized target first (unlike in Bonato et al., 2010). This allows to exclude that spatial omissions were caused by the delayed response or by interference from the concurrent task. Third, catch trials were introduced to exclude the presence of any response bias. Fourth, the single task was re-administered in the last block of the experiment, thereby allowing to exclude that lateralized deficits in spatial monitoring emerge during the task as a result of fatigue or drop in sustained attention. As a result of these changes, any direct comparison with previous data on RHD patients is problematic.

Though all LHD patients showed normal performance in a classic paper-and-pencil assessment battery for neglect, few of them (4 patients out of 10) showed extinction at baseline ("left" responses to bilateral targets in the single task), thereby revealing the high sensitivity of a test employing briefly presented targets which compete for awareness (Bonato \& Deouell, 2013). When a secondary visual task was introduced, one more patient showed extinction (for a total of $5 / 10$ cases with extinction). As expected, the dual-task paradigm also allowed to conclude with 
relatively high confidence that extinction was not present in some LHD patients. While this absence might be veridical, it is also possible that in some patients non-spatial attentional resources successfully compensated spatial deficits (Bonato, 2015).

While the finding of an extinction pattern seems consistent with the hypothesis of betweenhemifield competition in conditions of double simultaneous stimulation (Driver \& Vuilleumier, 2001; Kinsbourne, 1987; Miller, Gochin, \& Gross, 1993), the emergence of a pattern of right neglect under multitasking is particularly striking. Indeed, unilateral right targets are not subject to the bottom-up competition that characterizes bilateral targets. A significant asymmetry in the detection of unilateral targets in the single task was found only in three patients, whereas under visual load it was present in seven patients out of 10 . These results clearly show that subtracting non-spatial attentional resources to perform a concurrent task hinders visuospatial processing revealing attentional imbalances caused by the unilateral brain damage.

We propose that the effect of multitasking is best understood as an interaction between spatial and non-spatial components of attention. More specifically, our data converge in suggesting that concurrent task demands recruit non-spatial, supramodal attentional resources which are otherwise recruited to perform spatial monitoring. In the ERP study on healthy participants by Bonato et al. (2015), a load manipulation very similar to the one employed in the present study modulated the amplitude of the first positive component (P1) and shifted its neural generators, suppressing the signal in the early visual areas during both visual and auditory dual tasks. Later in stimulus processing, N2 contralateral components were particularly influenced by the concurrent visual task and were related to increased activation of the right supramarginal gyrus, suggesting a high sensitivity of the right hemisphere to load manipulations. Lisi, Bonato, and Zorzi, (2015) showed that the top-down allocation of supramodal attentional resources in a similar multitasking paradigm modulates pupil dilation. Cognitively-related pupil dilation has been linked to a neurotransmitter system, the locus coeruleus-noradrenergic neuromodulatory system (AstonJones \& Cohen, 2005), which is thought to have a central role in the functional integration of the attentional networks (Corbetta, Patel, \& Shulman, 2008).

The much higher prevalence of spatial neglect after right hemisphere compared to left hemisphere lesions has been classically attributed to brain asymmetries in spatial processing (Heilman \& Van Den Abell, 1979, Mesulam, 1981) or in interhemispheric inhibition (i.e., stronger inhibition by the right hemisphere; Kinsbourne, 1987). The pathological leftward bias observed in LHD patients suggests that the spared right hemisphere is unable to compensate for the left hemisphere damage, at least under multitasking. The interhemispheric inhibition model seems better suited to accommodate our findings if we assume that increasing attentional load boosts non-spatial, right-lateralized mechanisms, thereby increasing the imbalance in interhemispheric inhibition and causing stronger suppression of left hemisphere activity. 
It is worth noting, however, that the pathological leftward bias described here is unlikely to reflect an exacerbation of the subtle leftward bias described in healthy participants (i.e., pseudoneglect; Jewell \& McCourt, 2000, for a review). Indeed, the leftward bias in healthy participants turns into a rightward bias following increased cognitive load (Dodds et al., 2008; Peers, Cusack, \& Duncan, 2006). Thus, one viable explanation of the present results is that neural activity in the bilateral dorsal frontoparietal network, which is symmetrical in the healthy brain (Corbetta \& Shulman, 2011), becomes strongly asymmetrical under the joint influence of left hemisphere damage and increased left hemisphere inhibition induced by attentional load. Support to the interhemispheric competition account comes from the recent finding that fMRI-guided TMS over the left intraparietal sulcus induces a leftward spatial bias in healthy participants (Szczepanski \& Kastner, 2013).

A related, yet alternative, perspective to interpret the present findings can be found by referring to structural limits in the human brain - such as those hampering peripheral perception in healthy subjects under visual load (Lavie, 2005) - or amodal networks acting as central information bottlenecks (Dux et al., 2006; Tombu et al., 2011). These aspects are major determinants in several cognitive processes, including perception and spatial awareness, but typically their contribution in healthy participants is mostly detectable in terms of modulation of response times. The presence of neurological deficits can emphasize these structural limits and produce more striking behavioral effects, such as the inability to perceive a lateralized target. This is often the case in patients with USN, where the co-occurrence of core lateralized deficits and of non-spatial impairments (Husain \& Rorden, 2003) determine the complex clinical manifestations of USN.

Attentional disorders in patients with LHD are often considered infrequent, although previous evidence suggests they are not rare (Peers et al., 2005; Timpert et al., 2015), particularly in the subacute stage (Ringman et al., 2004). One might object that this difference is a consequence of excluding from the samples patients with severe linguistic disorders (who may fail to comply with task instructions), thereby describing only selected and overall less impaired patients (De Renzi, 1982, Bonato, Sella, Berteletti \& Umiltà, 2012). In a study on 80 unselected LHD patients, Beis and colleagues (2004) observed neglect in less than $15 \%$ of cases when considering either cancellation or drawing tasks alone. However, when the presence of neglect signs in any test was taken as diagnostic criterion, the percentage of patients presenting some degree of neglect increased to $40 \%$ (Beis et al., 2004). This indicates that lateralized attentional disorders might be revealed in a substantial proportion of LHD patients using a comprehensive screening battery and a more lenient diagnostic criterion. Here we showed that multitasking can reveal marked lateralized spatial deficits in a substantial proportion of LHD patients who do not show any sign of deficit at paper-and-pencil testing, which is the gold standard for neglect diagnosis. Given the ubiquity of multitasking in everyday activities, our approach can provide information that is clinically relevant (see Bonato et al., 2012, for a practical example). 
As a next step, a large-scale study should directly compare, using the same tasks, the rate of occurrence of lateralized disorders in RHD and LHD patients. A larger sample will also help in establishing the anatomical correlates of the deficits we described. Metaphorically speaking, the emergence of deficits under multitasking reminds of small icebergs whose real volume is much larger than the one above the water. Similarly, the full extent of spatial deficits suffered by patients with left hemisphere damage seems to become visible only when compensation is made impossible.

\subsection{ACKNOWLEDGMENTS}

This study was supported by grants from the University of Padova (Strategic Grant "NEURAT") and by the Italian Ministry of Health (RF-2013) to MZ. MB was supported by a Marie Curie Intra European Fellowship within the 7th European Community Framework Program. Funders had no role in experimental design, data collection, analysis or interpretation of the results.

\subsection{REFERENCES}

Aglioti, S., Smania, N., Barbieri, C., \& Corbetta, M. (1997). Influence of Stimulus Salience and Attentional Demands on Visual Search Patterns in Hemispatial Neglect. Brain and Cognition, 34(3), 388-403. http://doi.org/10.1006/brcg.1997.0915

Aston-Jones, G., \& Cohen, J. D. (2005). An integrative theory of locus coeruleusnorepinephrine function: adaptive gain and optimal performance. Annual Review Neuroscience, 28, 403-450.

Azouvi, P., Samuel, C., Louis-Dreyfus, A., Bernati, T., Bartolomeo, P., Beis, J.M., Chokron, S., Leclercq, M., Marchal, F., Martin, Y., De Montety, G., Olivier, S., Perennou, D., Pradat-Diehl, P., Prairial, C., Rode, G., Siéroff, E., Wiart, L., \& Rousseaux, M.; French Collaborative Study Group on Assessment of Unilateral Neglect (GEREN/GRECO) (2002). Sensitivity of clinical and behavioural tests of spatial neglect after right hemisphere stroke. Journal of Neurology, Neurosurgery \& Psychiatry, 73(2), 160-166. http://doi.org/10.1136/jnnp.73.2.160

Baayen, R. H., Davidson, D. J., \& Bates, D. M. (2008). Mixed-effects modeling with crossed random effects for subjects and items. Journal of Memory and Language, 59(4), 390412. http://doi.org/10.1016/j.jml.2007.12.005 
Bates, D., Maechler, M., Bolker, B., \& Walker, S. (2014). Ime4: Linear mixed-effects models using Eigen and S4. $R$ package version 1.1-7, <URL: http://CRAN.Rproject.org/package=Ime4>.

Bates, D., Kliegl, R., Vasishth, S., \& Baayen, H. (2015). Parsimonious Mixed Models. arXiv:1506.04967 [stat]. Retrieved from http://arxiv.org/abs/1506.04967

Beis, J.M., Keller, C., Morin, N., Bartolomeo, P., Bernati, T., Chokron, S., ... \& Azouvi, P.; French Collaborative Study Group on Assessment of Unilateral Neglect (GEREN/GRECO) (2004). Right spatial neglect after left hemisphere stroke: qualitative and quantitative study. Neurology, 63(9), 1600-1605.

Bonato, M. (2012). Neglect and Extinction Depend Greatly on Task Demands: A Review. Frontiers in Human Neuroscience, 6. http://doi.org/10.3389/fnhum.2012.00195

Bonato, M. (2015). Unveiling residual, spontaneous recovery from subtle hemispatial neglect three years after stroke. Frontiers in Human Neuroscience, 9. http://doi.org/10.3389/fnhum.2015.00413

Bonato, M., \& Deouell, L. Y. (2013). Hemispatial neglect: computer-based testing allows more sensitive quantification of attentional disorders and recovery and might lead to better evaluation of rehabilitation. Frontiers in Human Neuroscience, 7, 162. http://doi.org/10.3389/fnhum.2013.00162

Bonato, M., Priftis, K., Marenzi, R., Umiltà, C., \& Zorzi, M. (2010). Increased attentional demands impair contralesional space awareness following stroke. Neuropsychologia, 48(13), 3934-3940. http://doi.org/10.1016/j.neuropsychologia.2010.08.022

Bonato, M., Priftis, K., Marenzi, R., Umiltà, C., \& Zorzi, M. (2012). Deficits of contralesional awareness: A case study on what paper-and-pencil tests neglect. Neuropsychology, 26(1), 20. http://doi.org/10.1037/a0025306

Bonato, M., Priftis, K., Umiltà, C., \& Zorzi, M. (2013). Computer-based attentiondemanding testing unveils severe neglect in apparently intact patients. Behavioural Neurology, 26(3), 179-181. http://doi.org/10.3233/BEN-2012-129005

Bonato, M., Sella, F., Berteletti, I., \& Umiltà, C. (2012). Neuropsychology is nothing without control: A potential fallacy hidden in clinical studies. Cortex, 48(3), 353-355.

Bonato, M., Spironelli, C., Lisi, M., Priftis, K., \& Zorzi, M. (2015). Effects of Multimodal Load on Spatial Monitoring as Revealed by ERPs. PloS One, 10(9), e0136719.

Caffarra, P., Vezzadini, G., Dieci, F., Zonato, F., \& Venneri, A. (2014). Rey-Osterrieth complex figure: Normative values in an Italian population sample. Neurological Sciences, 22(6), 443-447. http://doi.org/10.1007/s100720200003

Carlesimo, G.A., Caltagirone, C., \& Gainotti, G.. The Mental Deterioration Battery: normative data, diagnostic reliability and qualitative analyses of cognitive impairment.The Group for the Standardization of the Mental Deterioration Battery. Eur Neurol., 36, 378-384. 
Chechlacz, M., Rotshtein, P., \& Humphreys, G. W. (2012). Neuroanatomical Dissections of Unilateral Visual Neglect Symptoms: ALE Meta-Analysis of Lesion-Symptom Mapping. Frontiers in Human Neuroscience, 6, 230. http://doi.org/10.3389/fnhum.2012.00230

Chechlacz, M., Terry, A., Demeyere, N., Douis, H., Bickerton, W.-L., Rotshtein, P., \& Humphreys, G. W. (2013). Common and distinct neural mechanisms of visual and tactile extinction: A large scale VBM study in sub-acute stroke. Neurolmage: Clinical, 2, 291-302. http://doi.org/10.1016/j.nicl.2013.01.013

Committeri, G., Pitzalis, S., Galati, G., Patria, F., Pelle, G., Sabatini, U., CastriotaScanderbeg, A., Piccardi, L., Guariglia, C., \& Pizzamiglio, L. (2007). Neural bases of personal and extrapersonal neglect in humans. Brain, 130(2), 431-441. http://doi.org/10.1093/brain/awl265

Corbetta, M., Kincade, M. J., Lewis, C., Snyder, A. Z., \& Sapir, A. (2005). Neural basis and recovery of spatial attention deficits in spatial neglect. Nature Neuroscience, 8(11), 16031610. http://doi.org/10.1038/nn1574

Corbetta, M., Patel, G., \& Shulman, G. L. (2008). The Reorienting System of the Human Brain: From Environment to Theory of Mind. Neuron, 58(3), 306-324. http://doi.org/10.1016/j.neuron.2008.04.017

Corbetta, M., \& Shulman, G. L. (2011). Spatial Neglect and Attention Networks. Annual Review of Neuroscience, 34(1), 569-599. http://doi.org/10.1146/annurev-neuro-061010-113731

Crawford, J. R., Garthwaite, P. H., Azzalini, A., Howell, D. C., \& Laws, K. R. (2006). Testing for a deficit in single-case studies: Effects of departures from normality. Neuropsychologia, 44(4), 666-677.

Crawford, J. R., \& Howell, D. C. (1998). Comparing an Individual's Test Score Against Norms Derived from Small Samples. The Clinical Neuropsychologist, 12(4), 482-486. http://doi.org/10.1076/clin.12.4.482.7241

De Renzi, E. (1982). Disorders of space exploration and cognition. New York: John Wiley \& Sons.

Dodds, C. M., van Belle, J., Peers, P. V., Dove, A., Cusack, R., Duncan, \& Manly, T. (2008). The effects of time-on-task and concurrent cognitive load on normal visuospatial bias. Neuropsychology, 22(4), 545. http://doi.org/10.1037/0894-4105.22.4.545

Driver, J., \& Vuilleumier, P. (2001). Perceptual awareness and its loss in unilateral neglect and extinction. Cognition, 79(1-2), 39-88. http://doi.org/10.1016/S0010-0277(00)001244

Dux, P. E., Ivanoff, J., Asplund, C. L., \& Marois, R. (2006). Isolation of a Central Bottleneck of Information Processing with Time-Resolved fMRI. Neuron, 52(6), 1109-1120. http://doi.org/10.1016/j.neuron.2006.11.009 
Ferber, S., \& Karnath, H.-O. (2001). How to Assess Spatial Neglect - Line Bisection or Cancellation Tasks? Journal of Clinical and Experimental Neuropsychology, 23(5), 599-607. http://doi.org/10.1076/jcen.23.5.599.1243

Friston, K.J., Ashburner, J., Kiebel, S.J., Nichols, T.E., \& Penny, W.D., editors. Statistical Parametric Mapping: The Analysis of Functional Brain Images. Academic Press, 2007.

Goedert, K. M., Boston, R. C., \& Barrett, A. M. (2013). Advancing the Science of Spatial Neglect Rehabilitation: An Improved Statistical Approach with Mixed Linear Modeling. Frontiers in Human Neuroscience, 7. http://doi.org/10.3389/fnhum.2013.00211

Halligan, P. W., Fink, G. R., Marshall, J. C., \& Vallar, G. (2003). Spatial cognition: evidence from visual neglect. Trends in Cognitive Sciences, 7(3), 125-133.

Heilman, K. M., \& Van Den Abell, T. (1979). Right hemispheric dominance for mediating cerebral activation. Neuropsychologia, 17(3-4), 315-321. http://doi.org/10.1016/00283932(79)90077-0

Heilman, K. M., Watson, R. T., \& Valenstein, E. (1985). Neglect and related disorders. In K. M. Heilman \& E. Valenstein (Eds.), Clinical neuropsychology (2nd ed.,pp. 243-293). New York: Oxford University Press.

Husain, M., \& Rorden, C. (2003). Non-spatially lateralized mechanisms in hemispatial neglect. Nature Reviews Neuroscience, 4(1), 26-36. http://doi.org/10.1038/nrn1005

Jewell, G., \& McCourt, M. E. (2000). Pseudoneglect: a review and meta-analysis of performance factors in line bisection tasks. Neuropsychologia, 38(1), 93-110.

Kaplan, R. F., Verfaellie, M., Meadows, M. E., Caplan, L. R., Pessin, M. S., \& DeWitt, L. D. (1991). Changing attentional demands in left hemispatial neglect. Archives of Neurology, 48(12), 1263-1266.

Karnath, H.-O., Rennig, J., Johannsen, L., \& Rorden, C. (2011). The anatomy underlying acute versus chronic spatial neglect: A longitudinal study. Brain, 134(3), 903-912. http://doi.org/10.1093/brain/awq355

Kinsbourne, M. (1987). Mechanisms of Unilateral Neglect. In M. Jeannerod (Ed.), Advances in Psychology (Vol. 45, pp. 69-86). North-Holland. Retrieved from http://www.sciencedirect.com/science/article/pii/S0166411508617094

Làdavas, E. (1990). Selective spatial attention in patients with visual extinction. Brain, 113(5), 1527-1538. http://doi.org/10.1093/brain/113.5.1527

Lavie, N. (2005). Distracted and confused?: Selective attention under load. Trends in Cognitive Sciences, 9(2), 75-82. http://doi.org/10.1016/j.tics.2004.12.004

Laws, K. R. (2005). Categories, controls and ceilings. Cortex, 41(6), 869-872.

Linden, D. E. J. (2007). The Working Memory networks of the human brain. The Neuroscientist, 13(3), 257-267. http://doi.org/10.1177/1073858406298480 
Lisi, M., Bonato, M., \& Zorzi, M. (2015). Pupil dilation reveals top-down attentional load during spatial monitoring. Biological Psychology, 112, 39-45. http://doi.org/10.1016/j.biopsycho.2015.10.002

Luzzatti, C., Willmes, K., \& De Bleser, R. (1996). Aachener aphasie test. Italian Version Firenze, Italy: Organizzazioni Speciali.

Magni, E., Binetti, G., Bianchetti, A., Rozzini, R., \& Trabucchi, M. (1996). Mini-Mental State Examination: a normative study in Italian elderly population. European Journal of Neurology, 3(3), 198-202. http://doi.org/10.1111/j.1468-1331.1996.tb00423.x

Marois, R., \& Ivanoff, J. (2005). Capacity limits of information processing in the brain. Trends in Cognitive Sciences, 9(6), 296-305. http://doi.org/10.1016/j.tics.2005.04.010

Mesulam, M. M. (1981). A cortical network for directed attention and unilateral neglect. Annals of neurology, 10(4), 309.

Miller, E. K., Gochin, P. M., \& Gross, C. G. (1993). Suppression of visual responses of neurons in inferior temporal cortex of the awake macaque by addition of a second stimulus. Brain Research, 616(1-2), 25-29. http://doi.org/10.1016/0006-8993(93)90187-R

Molenberghs, P., Sale, M. V., \& Mattingley, J. B. (2012). Is there a critical lesion site for unilateral spatial neglect? A meta-analysis using activation likelihood estimation. Frontiers in Human Neuroscience, 6, 78. http://doi.org/10.3389/fnhum.2012.00078

Mort, D. J., Malhotra, P., Mannan, S. K., Rorden, C., Pambakian, A., Kennard, C., \& Husain, M. (2003). The anatomy of visual neglect. Brain, 126(9), 1986-1997. http://doi.org/10.1093/brain/awg200

Nachev, P., Coulthard, E., Jäger, H. R., Kennard, C., \& Husain, M. (2008). Enantiomorphic normalization of focally lesioned brains. Neurolmage, 39(3), 1215-1226. http://doi.org/10.1016/j.neuroimage.2007.10.002

Oldfield, R. C. (1971). The assessment and analysis of handedness: The Edinburgh inventory. Neuropsychologia, 9(1), 97-113. http://doi.org/10.1016/0028-3932(71)90067-4

Peers, P. V., Cusack, R., \& Duncan, J. (2006). Modulation of spatial bias in the dual task paradigm: Evidence from patients with unilateral parietal lesions and controls. Neuropsychologia, 44(8), 1325-1335. http://doi.org/10.1016/j.neuropsychologia.2006.01.033

Peers, P. V., Ludwig, C. J., Rorden, C., Cusack, R., Bonfiglioli, C., Bundesen, C., Driver, J., Nagui, A., \& Duncan, J. (2005). Attentional functions of parietal and frontal cortex. Cerebral Cortex, 15(10), 1469-1484.

Petersen, R. C. (2004). Mild cognitive impairment as a diagnostic entity. Journal of Internal Medicine, 256(3), 183-194. http://doi.org/10.1111/j.1365-2796.2004.01388.x

R Core Team (2015). R: A language and environment for statistical computing. $R$ Foundation for Statistical Computing, Vienna, Austria. URL http://www.R-project.org/. 
Rapcsak, S.Z., Verfaellie, M., Fleet, S., \& Heilman, K.M. (1989). Selective attention in hemispatial neglect. Archives of Neurology, 46(2), 178-182. http://doi.org/10.1001/archneur.1989.00520380082018

Redel, P., Bublak, P., Sorg, C., Kurz, A., Förstl, H., Müller, H. J., ... \& Finke, K. (2012). Deficits of spatial and task-related attentional selection in mild cognitive impairment and Alzheimer's disease. Neurobiology of Aging, 33(1), 195-e27.

Ringman, J. M., Saver, J. L., Woolson, R. F., Clarke, W. R., \& Adams, H. P. (2004). Frequency, risk factors, anatomy, and course of unilateral neglect in an acute stroke cohort. Neurology, 63(3), 468-474. http://doi.org/10.1212/01.WNL.0000133011.10689.CE

Robertson, I. H. (2014). A right hemisphere role in cognitive reserve. Neurobiology of Aging, 35(6), 1375-1385. http://doi.org/10.1016/j.neurobiolaging.2013.11.028

Robertson, I., \& Frasca, R. (1991). Attentional load and visual neglect. International Journal of Neuroscience, 62(1-2), 45-56.

Robertson, I. H., Manly, T., Beschin, N., Daini, R., Haeske-Dewick, H., Hömberg, V., Jehkonen, M., Pizzamiglio, G., Shiel, A., \& Weber, E. (1997). Auditory sustained attention is a marker of unilateral spatial neglect. Neuropsychologia, 35(12), 1527-1532. http://doi.org/10.1016/S0028-3932(97)00084-5

Robertson, I. H., Mattingley, J. B., Rorden, C., \& Driver, J. (1998). Phasic alerting of neglect patients overcomes their spatial deficit in visual awareness. Nature, 395(6698), 169172. http://doi.org/10.1038/25993

Robertson, I. H., Tegnér, R., Tham, K., Lo, A., \& Nimmo-smith, I. (2008). Sustained attention training for unilateral neglect: Theoretical and rehabilitation implications. Journal of Clinical and Experimental Neuropsychology. http://doi.org/10.1080/01688639508405133

Rorden, C., Bonilha, L., Fridriksson, J., Bender, B., \& Karnath, H.-O. (2012). Age-specific CT and MRI templates for spatial normalization. Neurolmage, 61(4), 957-965. http://doi.org/10.1016/j.neuroimage.2012.03.020

Rorden, C., \& Brett, M. (2000). Stereotaxic display of brain lesions. Behavioural Neurology, 12(4), 191-200.

Sarri, M., Greenwood, R., Kalra, L., \& Driver, J. (2009). Task-related modulation of visual neglect in cancellation tasks. Neuropsychologia, 47(1), 91-103. http://doi.org/10.1016/j.neuropsychologia.2008.08.020

Spence, C. (2008). Cognitive Neuroscience: Searching for the Bottleneck in the Brain. Current Biology, 18(20), R965-R968. http://doi.org/10.1016/j.cub.2008.08.039

Stern, Y. (2002). What is cognitive reserve? Theory and research application of the reserve concept. Journal of the International Neuropsychological Society, 8(03), 448-460. http://doi.org/10.1017/S1355617702813248 
Stone, S. P., Halligan, P. W., \& Greenwood, R. J. (1993). The incidence of neglect phenomena and related disorders in patients with an acute right or left hemisphere stroke. Age and Ageing, 22(1), 46-52. http://doi.org/10.1093/ageing/22.1.46

Szczepanski, S. M., \& Kastner, S. (2013). Shifting attentional priorities: Control of spatial attention through hemispheric competition. The Journal of Neuroscience, 33(12), 5411-5421.

Thimm, M., Fink, G. R., Küst, J., Karbe, H., \& Sturm, W. (2006). Impact of alertness training on spatial neglect: A behavioural and fMRI study. Neuropsychologia, 44(7), 1230-1246. http://doi.org/10.1016/j.neuropsychologia.2005.09.008

Timpert, D. C., Weiss, P. H., Vossel, S., Dovern, A., \& Fink, G. R. (2015). Apraxia and spatial inattention dissociate in left hemisphere stroke. Cortex, 71, 349-358. doi: 10.1016/j.cortex.2015.07.023

Tombu, M. N., Asplund, C. L., Dux, P. E., Godwin, D., Martin, J. W., \& Marois, R. (2011). A Unified attentional bottleneck in the human brain. Proceedings of the National Academy of Sciences, 108(33), 13426-13431. http://doi.org/10.1073/pnas.1103583108

Vallar, G. (1998). Spatial hemineglect in humans. Trends in Cognitive Sciences, 2(3), 87-97.

Weintraub, S., \& Mesulam, M.-M. (1987). Right cerebral dominance in spatial attention: Further evidence based on ipsilateral neglect. Archives of Neurology, 44(6), 621-625. http://doi.org/10.1001/archneur.1987.00520180043014

Wilson, B., Cockburn, J., \& Halligan, P. W. (1987). Behavioural Inattention Test. (Thames Valley Test Company, Titchfield, Hants.).

Zorzi, M., Bonato, M., Treccani, B., Scalambrin, G., Marenzi, R., \& Priftis, K. (2012). Neglect impairs explicit processing of the mental number line. Frontiers in Human Neuroscience, 6, 125. http://doi.org/10.3389/fnhum.2012.00125 